\section{IS THERE A NEED FOR IDENTITY CARDS?}

The present UK government appears determined to introduce a compulsory registration card, having introduced the Identity Cards Bill to Parliament. The specified purposes of the National Identity Register which the Bill creates (in $\mathrm{c} 1(3)$ ) are to provide a convenient method for individuals to prove their identity, and the provision of a secure means of identifying individuals where that is in the public interest. Clause 1(4) defines the public interest as covering national security; the prevention and detection of crime; the enforcement of immigration controls; enforcements on prohibitions on unauthorised working or employment; and the efficient and effective provision of public services. The first two categories include action to prevent terrorism, and the second covers identity fraud and theft.

The proponent of an idea has the burden of proving the concept has a value and will solve a problem, especially when the idea will cost considerable amounts of money. However, no government minister has offered a soundly argued case for the introduction of a registration card in the UK to date. I considered the issue of whether a need for identity card existed in a two-part article published in Computer Fraud and Security last year (see August 2004, 9-15 and September 2004, 8-14). Some of the key points I made are summarised here.

Of particular interest is the concept of proving individual identity. We are familiar with a wide range of documents in the 21 st century, but all they do is record the name of an individual. No document acts to establish proof of identity, not even a birth certificate. All a registration card will demonstrate is that an individual might have attended a designated centre to have recordings taken of such biometric measurements of their body as are deemed required, and that they presented a sufficient number of other forms of record. The act of registration cannot serve to link an individual to a piece of plastic called an "identity card". It only records the process of registration.

The two most frequent reasons for introducing a registration card have been to prevent terrorism and crime. However, there is no correlation between acts of terrorism and the absence of a registration system, as was noted in a report published last year by Privacy International. This points out that six countries have an identity card and include a biometric measurement in some way, yet they all suffered from terrorist acts.

Identity fraud can be divided into three main categories: "account takeover", where a thief obtains access to a person's accounts; "true name", where a thief uses an item of personal information that serves to identify the victim; and "covering tracks", where a criminal commits crimes using the identity of an innocent person. For the purposes of the current exercise the government has not defined

\section{Articles \\ Pleas bargaining, discretionary leniency and the making of political authority \\ A mixed legal system with a constitution on top: \\ South African law in the era of democracy \\ Society and Institute News \\ 14 \\ Articles (cont'd) \\ The politicisation of UK immigration policy \\ Management and control in Italian public companies

what is meant by identity fraud. Proponents of a registration card have failed to demonstrate how a registration card will serve to reduce the various frauds committed in the public and private sectors, which include money laundering using multiple identities. Importantly, no evidence has been adduced by the government to demonstrate those countries that already have a registration card can show lower levels of crime than those without a comparable system.

As for controlling immigrant working, the introduction of a registration card will not stop employers flouting the law by employing workers with no entitlement to work. The government places a great deal of reliance on the use of biometric measures, but there is little experience in the widespread deployment of systems involving biometrics and large population databases. The consultation paper Entitlement cards and identity fraud accepts it is debateable that a registration card will deter people from committing crime, but it is seen as helping police to verify the identity of an individual when stopped. However, it is acknowledged in the same report that this is not usually much of a problem for the police because they already know the vast majority of the people they come into contact with.

So far, public opinion is broadly in favour of registration cards, but it should be remembered that the Australian government made similar claims about the proposed introduction of a national scheme in the 1980s. A majority of people rejected the idea once the full ramifications became apparent.

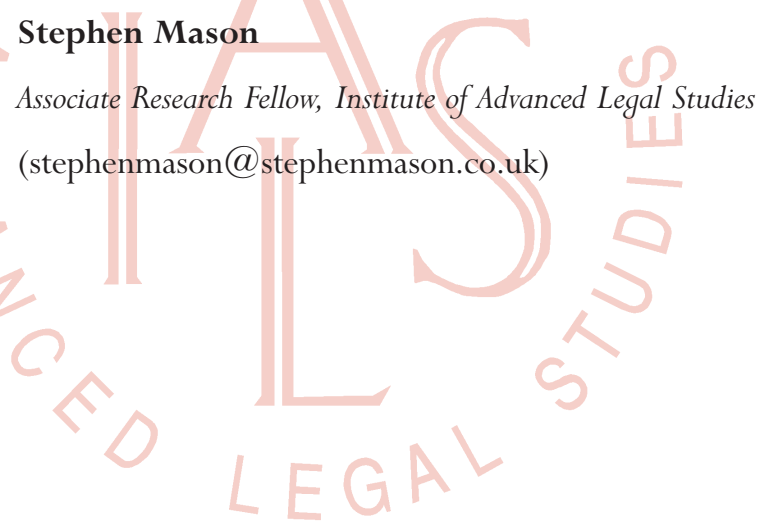

